\title{
Biological differences between melancholic and nonmelancholic depression subtyped by the CORE measure
}

This article was published in the following Dove Press journal:

Neuropsychiatric Disease and Treatment

19 August 2014

Number of times this article has been viewed

\author{
Lucas Spanemberg ${ }^{1,2}$ \\ Marco Antonio Caldieraro \\ Edgar Arrua Vares' \\ Bianca Wollenhaupt- \\ Aguiar ${ }^{3,4}$ \\ Márcia Kauer-Sant'Anna ${ }^{3,4}$ \\ Sheila Yuri Kawamoto' \\ Emily Galvão3-5 \\ Gordon Parker 6,7 \\ Marcelo P Fleck ${ }^{1,8}$ \\ 'Mood Disorders Program, Hospital \\ de Clínicas de Porto Alegre, \\ Universidade Federal do Rio Grande \\ do Sul, ${ }^{2}$ Department of Psychiatry, \\ Hospital São Lucas da Pontifícia \\ Universidade Católica do Rio Grande \\ do Sul, 'INCT Translational Medicine, \\ Hospital de Clínicas de Porto Alegre, \\ ${ }^{4}$ Bipolar Disorders Program and \\ Laboratory of Molecular Psychiatry, \\ Universidade Federal do Rio Grande \\ do Sul, ${ }^{5}$ Centro Universitário \\ Metodista, Porto Alegre, Brazil; \\ ${ }^{6}$ School of Psychiatry, University \\ of New South Wales, ${ }^{7}$ Black Dog \\ Institute, Sydney, NSW, Australia; \\ ${ }^{8}$ Neuromodulation Research Clinic, \\ Douglas Mental Health University \\ Institute, Montréal, ON, Canada
}

Correspondence: Lucas Spanemberg Psychiatric Unit, $6^{\circ}$ andar sul, Hospital São Lucas da PUCRS, Porto Alegre, RS 906। 0-000, Brazil

Tel +55 5l 3320304 I

Email Ispanemberg@yahoo.com.br
Background: The purpose of this study was to compare melancholic patients rated by the CORE measure of observable psychomotor disturbance with nonmelancholic and control subjects across a set of biomarkers.

Methods: Depressed patients were classified as melancholic or nonmelancholic by using the CORE measure. Both groups of patients, as well as control subjects, were compared for a set of clinical and laboratory measures. Serum levels of brain-derived neurotrophic factor, of two markers of oxidative stress (protein carbonyl content [PCC] and thiobarbituric acid reactive substances [TBARS]), and of several immunity markers (interleukin [IL]-2, IL-4, IL-6, IL-10, IL-17, tumor necrosis factor-alpha, and interferon-gamma) were analyzed.

Results: Thirty-three depressed patients and 54 healthy controls were studied. Depressive patients showed higher IL-4, IL-6, and PCC values than healthy controls. Thirteen (39\%) of the depressed patients were assigned as melancholic by the CORE measure. They generated lower interferon-gamma (compared with nonmelancholic depressed patients) and TBARS (compared with both the nonmelancholic subset and controls) and returned higher IL-6 levels than controls. Both depressive groups generated higher PCC scores than controls, with no difference between melancholic and nonmelancholic subsets.

Conclusion: A sign-based measure to rate melancholia was able to replicate and extend biological findings discriminating melancholic depression. Signs of psychomotor disturbance may be a useful diagnostic measure of melancholia.

Keywords: melancholic depression, oxidative stress, inflammatory cytokines, brain-derived neurotrophic factor

\section{Introduction}

Since the introduction of the DSM-III (Diagnostic and Statistical Manual of Mental Disorders, Third Edition) in the early 1980s, major depressive disorder has been conceptualized as a unitary entity. ${ }^{1,2}$ However, there have been a growing number of studies that support revising this model to position melancholia as a distinct depressive subtype. ${ }^{1,3}$ A number of studies have reported clinical ${ }^{4-8}$ and biological ${ }^{7,9-11}$ differences between patients with melancholic and nonmelancholic depression, and argued for differing underlying pathophysiological processes. ${ }^{12}$ However, while there is increasing appreciation of melancholia as a distinct entity, ${ }^{13}$ its validity involves more precise clinical and biological definition.

While the melancholic subtype (also classically known as "endogenous", "autonomous", or "type A" depression) has been historically used to name a clinical presentation of depression characterized by specific signs and symptoms 
(eg, nonreactivity of mood, anhedonia, and psychomotor disturbance), its putative pathophysiology has imputed a large number of potential genetic and other biological determinants. ${ }^{14}$ For example, several studies have implicated an abnormal dexamethasone suppression test, ${ }^{15,16}$ changes in plasma levels of neuroactive amino acids and nitric oxide, ${ }^{17}$ hypercortisolism, ${ }^{11,18}$ and selective responsivity to physical treatments, such as antidepressant drugs ${ }^{19}$ and electroconvulsive therapy. ${ }^{20,21}$ However, other biological markers have been less studied or generated less consistent findings.

Serum brain-derived neurotrophic factor (BDNF) has been reported consistently as being low in depressive patients, ${ }^{22}$ but very few studies have compared BDNF in depressive subtypes. While Bus et al found no differences between depressive groups, ${ }^{23}$ Patas et $\mathrm{al}^{24}$ reported lower levels in nonmelancholic depressive patients compared with a control group, but no difference between melancholic and nonmelancholic depressive subtypes. There has also been a lack of studies investigating differences in oxidative stress markers between melancholic and nonmelancholic depression, although there is a growing body of evidence considering depression as an inflammatory disorder. ${ }^{25}$

Another growing line of research has involved investigating immune parameters across melancholic and nonmelancholic subtypes. However, while several studies have found higher proinflammatory immune activation in nonmelancholic depression, ${ }^{10,26,27}$ contradictory findings have been reported in relation to inflammatory markers. While interleukin (IL)-6 has been reported to be increased ${ }^{11,27,28}$ or normal $^{29}$ in melancholic patients, other markers of T helper lymphocyte 1 (Th1) proinflammatory response, such as tumor necrosis factor-alpha (TNF- $\alpha$ ) and interferon-gamma (IFN- $\gamma$ ), have been reported as increased, ${ }^{30}$ nondifferentiating,,${ }^{29,31,32}$ or decreased ${ }^{10,27}$ in melancholic samples. The same variability in findings is evident for T helper lymphocyte 2 (Th2) antiinflammatory markers, such as IL-10, ${ }^{10,31,33}$ as well as other Th1 cytokines such as IL-1 $1^{9,29-31,34}$ and IL-2. ${ }^{10,35}$

One possible cause of the contradictory results may be the limited discriminatory power of the symptom-based DSM diagnosis of melancholia, being used in almost all reported studies, and which remains practically unchanged in DSM-5. ${ }^{36}$ In its classical definition, melancholia has as a "core" feature observable psychomotor disturbance (PMD, ie, a sign rather than a symptom). ${ }^{37}$ In several studies, Parker et al demonstrated a sign-based approach as being more precise in diagnosing melancholia than symptom-based criteria sets, ${ }^{38}$ and suggested that the latter may confound interpretation of investigatory neurobiological studies. ${ }^{3}$ They developed and validated the CORE measure, ${ }^{38}$ now one of the most widely used measures of PMD in melancholia.,5,39-41 However, few studies involving the CORE measure have evaluated biological parameters. Joyce et al reported that patients with CORE-defined melancholia, but not if subtyped by DSM-IV criteria, had greater neuroendocrine dysfunction, ${ }^{40}$ with a blunted thyroid-stimulating hormone response after infusion of thyrotrophin-releasing hormone and higher afternoon cortisol levels. Mitchell ${ }^{42}$ reported a higher rate of nonsuppression on the dexamethasone suppression test in melancholic patients defined by the CORE measure, but not by DSM-III criteria. While many studies link depression with immune dysregulation ${ }^{43-45}$ via an imbalanced production of proinflammatory/anti-inflammatory cytokines, neurotrophin changes, ${ }^{46,47}$ and increased oxidative stress, ${ }^{48,49}$ there are no studies examining these biological markers in relation to the CORE measure. In summary, despite evidence supporting melancholia as a distinctive depressive subtype, neurobiological differences between melancholic and nonmelancholic depression remain unclear.

Therefore, the aim of this study was to compare potential neurobiological parameters of melancholic and nonmelancholic depressed patients subtyped by the CORE measure and also as compared with controls. The study compares data for three neurobiological parameters not previously studied by the CORE measure: examining neurotrophins (BDNF), oxidative stress (protein carbonyl content [PCC] and thiobarbituric acid reactive substances [TBARS]), and immune system (IL-2, IL-4, IL-6, IL-10, IL-17, TNF- $\alpha$, and IFN- $\gamma$ ) variables.

\section{Materials and methods Patients and assessment}

Depressive patients were recruited at the Mood Disorders Program, an outpatient facility based at the Hospital de Clínicas de Porto Alegre (HCPA), Brazil. A diagnosis of unipolar depression was accorded by DSM-IV criteria and rated by the Mini International Neuropsychiatric Interview, Brazilian version (MINI-Plus) ${ }^{50}$ All depressed patients were classified as melancholic or nonmelancholic according to the CORE measure that evaluates 18 observable features of melancholia on a four-point scale, measuring its absence (" 0 ") or presence (three levels of severity, from 1 to 3 ). ${ }^{38}$ Examples of items include facial nonreactivity, facial apprehension, and delay in motor activity. Three authors (LS, MAC, EAV) were trained by video and printed guidelines provided by the Black Dog Institute. ${ }^{51}$ A CORE score $\geq 8$ was adopted in this study as defining melancholia, according 
to CORE development studies. ${ }^{52}$ Depressive symptoms were evaluated using the 17-item Hamilton Depression Rating Scale (HDRS-17). ${ }^{53}$ A HDRS-17 $\geq 18$ indicating moderate to severe depression was considered as an inclusion criterion for this study. ${ }^{54}$ Exclusion criteria included any history of autoimmune disease, chronic infection, or an inflammatory disorder, as well as any severe systemic disease or use of immunosuppressive therapy. We also recruited a control group consisted of 54 healthy volunteers attending the HCPA blood donor center, who had no current or previous history as well as no first-degree family history of a major psychiatric disorder, including dementia or mental retardation, assessed by the nonpatient version of the Structured Clinical Interview for DSM-IV.

The investigation was approved by the medical ethics committee at HCPA, and all participants provided written informed consent. All laboratory tests were performed at the Laboratory of Molecular Psychiatry, HCPA.

\section{Collection and processing of blood}

Ten milliliters of blood were collected from each patient and control by venipuncture into a free-anticoagulant vacuum tube. Immediately after withdrawal, the blood was centrifuged at 4,000 rpm for 10 minutes and serum was aliquoted, labeled, and stored at $-80^{\circ} \mathrm{C}$ until assayed.

\section{Cytokine assay}

Serum cytokine concentrations were determined by flow cytometry using the BD ${ }^{\mathrm{TM}}$ cytometric bead array Th1/Th2/ Th17 Human Cytokine kit (BD Biosciences, San Diego, CA, USA). The cytometric bead array kit employed allows discrimination of the following cytokines: IL-2, IL-4, IL-6, IL-10, TNF- $\alpha$, IFN- $\gamma$, and IL-17A. Sample processing and data analyses were performed following the manufacturer's guidelines using a FACSCalibur flow cytometer (BD Biosciences). Results were generated in graphical and tabular format using FCAP Array ${ }^{\mathrm{TM}}$ cytometric bead array analysis software (BD Biosciences).

\section{BDNF measurement}

Serum concentrations of BDNF were measured by sandwich enzyme-linked immunosorbent assay using monoclonal antibodies specific for BDNF from R\&D Systems (Minneapolis, MN, USA). Human BDNF monoclonal antibody (clone 37129), a mouse immunoglobulin G2a, was used as the capture antibody, and the human BDNF biotinylated monoclonal antibody (clone 37141), a mouse immunoglobulin G2a, was used as the detection antibody.
The amount of BDNF was determined by absorbance at $450 \mathrm{~nm}$ with a correction at $540 \mathrm{~nm}$, and the standard curve demonstrated a direct relationship between optical density and BDNF concentration.

\section{Thiobarbituric acid reactive substances assay}

The levels of lipid peroxidation were measured using the TBARS assay kit (Cayman Chemical Company, Ann Arbor, MI, USA), according to the manufacturer's instructions. The results are expressed in $\mu \mathrm{M}$ of malondialdehyde.

\section{Protein carbonyl content}

Oxidative damage to proteins was analyzed by determination of carbonyl groups (PCC method for carbonyl content in proteins), as previously described by Levine et al. ${ }^{55}$ Analyses were performed in serum samples and the values expressed in $\mathrm{nmol} / \mathrm{mg}$ of protein.

\section{Statistical analyses}

All analyses were performed using Statistical Package for the Social Sciences version 18 software (SPSS Inc, Chicago, IL, USA). The normality of data distribution was examined by the Shapiro-Wilk test. ${ }^{56}$ The chi-square or Fisher's exact test was used to analyze the association between dichotomous categorical variables. The Student's $t$-test was used to compare means between unpaired groups. The Mann-Whitney $U$-test was used to compare nonparametric variables between two groups. One-way analysis of variance followed by the Tukey post hoc test was used for comparison of parametric variables among three or more groups, and the Kruskal-Wallis test was used for nonparametric variables. Quantitative variables were expressed as the mean \pm standard deviation or median and interquartile range, according to the sample distribution. In all experiments, $P$-values less than 0.05 were considered to indicate statistical significance.

\section{Results}

Data from a total of 33 depressed patients were analyzed after application of inclusion and exclusion criteria. According to the CORE measure, 13 (39.3\%) patients were melancholic. Demographic and clinical variable data are presented in Table 1. There were no significant differences between patient groups with regard to age, female sex, HRSD-17, lifetime tobacco use, body mass index, time of current episode, number of previous episodes, and medication use. While CORE-defined melancholic patients had more psychotic episodes than nonmelancholic patients $(30.8 \%$ versus $10 \%$, respectively), this difference was not significant. 
Table I Sociodemographic and clinical variables for depressive and control groups

\begin{tabular}{|c|c|c|c|c|}
\hline & \multirow{2}{*}{$\begin{array}{l}\text { Control } \\
(n=54)\end{array}$} & \multicolumn{2}{|l|}{ CORE subtypes } & \multirow[t]{2}{*}{$P$-value } \\
\hline & & $\begin{array}{l}\text { Nonmelancholic } \\
(n=20)\end{array}$ & $\begin{array}{l}\text { Melancholic } \\
(n=13)\end{array}$ & \\
\hline Age (years) & $47.4 \pm 9.97$ & $48.4 \pm 7.7$ & $52.8 \pm 10.7$ & $0.20^{c}$ \\
\hline Female sex & $74.1 \%$ & $90.0 \%$ & $76.9 \%$ & $0.33^{\mathrm{a}}$ \\
\hline HDRS & NA & $21.8 \pm 2.9$ & $22.6 \pm 2.9$ & $0.8 \mathrm{I}^{\mathrm{b}}$ \\
\hline Lifetime tobacco use & NA & $55 \%$ & $53.8 \%$ & $1.0^{\mathrm{a}}$ \\
\hline BMI & NA & $26.4 \pm 0.9$ & $27.4 \pm 4.4$ & $0.5 \mathrm{I}^{\mathrm{b}}$ \\
\hline Psychotic depression & - & $10 \%$ & $30.8 \%$ & $0.18^{\mathrm{a}}$ \\
\hline CORE (mean) & NA & $3.4 \pm 2.5$ & $\mid 3.1 \pm 5.0$ & $<0.00 l^{d}$ \\
\hline Time current episode (average months) & - & $20.0 \pm 18.1$ & $29.0 \pm 36.3$ & $0.65^{d}$ \\
\hline Episodes (n) & 0 & $6.7 \pm 7.9$ & $4.3 \pm 4.7$ & $0.43^{d}$ \\
\hline \multicolumn{5}{|l|}{ Proportion on } \\
\hline Any AD & 0 & $90 \%$ & $84.6 \%$ & $1.0^{\mathrm{a}}$ \\
\hline $\mathrm{TCA}$ & 0 & $50.0 \%$ & $53.8 \%$ & $1.0^{\mathrm{a}}$ \\
\hline SSRIs & 0 & $65.0 \%$ & $53.8 \%$ & $0.4 I^{\mathrm{a}}$ \\
\hline Other AD & 0 & $12.1 \%$ & $0 \%$ & $0.13^{\mathrm{a}}$ \\
\hline Lithium & 0 & $15.0 \%$ & $23.1 \%$ & $0.65^{\mathrm{a}}$ \\
\hline Anticonvulsants & 0 & $45.0 \%$ & $46.2 \%$ & $1.0^{\mathrm{a}}$ \\
\hline Antipsychotics & 0 & $25.0 \%$ & $38.5 \%$ & $0.46^{\mathrm{a}}$ \\
\hline
\end{tabular}

Notes: Analysis of age and sex comparing three groups, ie, control, nonmelancholic, and melancholic groups; all other variables were analyzed comparing two groups,

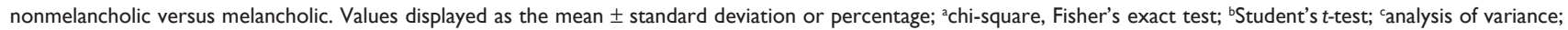
dMann-Whitney U-test.

Abbreviations: NA, not assessed; HDRS, Hamilton Depressive Rating Scale; BMI, body mass index; AD, antidepressant; TCA, tricyclic antidepressant; SSRIs, selective serotonin reuptake inhibitors.

Our first strategy was to compare the biological parameters between depressed patients (irrespective of depressive subset) and healthy controls. Table 2 data quantify that depressed patients had significantly higher levels than controls on the PCC, IL-4, and IL-6 variables. There were no differences in other examined biological measures.

Laboratory variables for the three groups are presented in Table 3. Nonmelancholic patients and controls returned higher INF- $\gamma$ values than melancholic patients, while the controls and nonmelancholic patients did not differ from each other. Melancholic but not nonmelancholic patients returned higher IL-6 values than controls. Melancholic patients generated lower TBARS values than nonmelancholic patients, but there was no difference between the depressive subset and control groups. Both depressive groups showed significantly higher PCC values than controls but did not differ between melancholic and nonmelancholic groups. There was no statistically significant difference in BDNF, IL-2, IL-4, IL-10, TNF- $\alpha$, and IL-17 levels between melancholic and nonmelancholic groups.

\section{Discussion}

We analyzed biological markers in relation to melancholic and nonmelancholic depression subtyped by a sign-based measure of melancholia. To our knowledge, this is the first study evaluating inflammatory markers, neurotrophins, and oxidative stress in melancholic depression using a sign-based diagnostic tool, ie, the CORE measure. This is also the first study comparing oxidative stress parameters (TBARS and PCC) irrespective of diagnostic system between melancholic and nonmelancholic groups.

Table 2 Serum biological data comparing depressive versus control groups

\begin{tabular}{llll}
\hline & $\begin{array}{l}\text { Control } \\
(\mathbf{n}=\mathbf{5 4})\end{array}$ & $\begin{array}{l}\text { Depressive } \\
(\mathbf{n}=\mathbf{3 3})\end{array}$ & P-value \\
\hline BDNF & $25.1 \mathrm{I} \pm 7.76$ & $26.10 \pm 7.40$ & 0.560 \\
TBARS & $10.26(4.00)$ & $10.26(4.66)$ & 0.871 \\
PCC & $0.03(0.03)$ & $0.69(0.05)$ & $<0.00$ I** $^{*}$ \\
IL-2 & $0.25(0.08)$ & $0.27(0.11)$ & 0.578 \\
IL-4 & $0.64(0.21)$ & $0.75(0.30)$ & $0.026^{*}$ \\
IL-6 & $0.88(0.69)$ & $1.28(1.27)$ & $0.004^{* *}$ \\
IL-I0 & $0.37(0.26)$ & $0.32(0.28)$ & 0.564 \\
TNF- $\alpha$ & $0.98(0.30)$ & $0.99(0.26)$ & 0.997 \\
IFN- $\gamma$ & $1.64(0.34)$ & $1.60(0.29)$ & 0.316 \\
IL-I7 & $12.84(17.18)$ & $7.87(9.50)$ & 0.089 \\
\hline
\end{tabular}

Notes: BDNF is displayed as the mean \pm standard deviation; other variables are displayed as the median and interquartile range. The statistical tests used were oneway analysis of variance test for BDNF and the Kruskal-Wallis test for other variables. $* P<0.05 ; * * P<0.005$.

Abbreviations: BDNF, brain-derived neurotrophic factor; TBARS, thiobarbituric acid reactive substances; PCC, protein carbonyl content; IL-2, interleukin-2; IL-4, interleukin-4; IL-6, interleukin-6; IL- I0, interleukin- I0; IL- I7, interleukin- I7; TNF- $\alpha$, tumor necrosis factor-alpha; IFN- $\gamma$, interferon-gamma. 
Table 3 Serum biological data returned by CORE-defined melancholic and nonmelancholic subsets and in comparison with control group

\begin{tabular}{|c|c|c|c|c|c|}
\hline & \multirow{2}{*}{$\begin{array}{l}\text { Control } \\
(n=54)\end{array}$} & \multicolumn{2}{|c|}{ Subtypes according to CORE model } & \multirow[t]{2}{*}{$P$-value } & \multirow{2}{*}{$\begin{array}{l}\text { Post hoc } \\
\text { differences }\end{array}$} \\
\hline & & $\begin{array}{l}\text { Nonmelancholic } \\
(n=20)\end{array}$ & $\begin{array}{l}\text { Melancholic } \\
(n=13)\end{array}$ & & \\
\hline BDNF & $25.11 \pm 7.76$ & $25.8 \pm 7.5$ & $26.5 \pm 7.4$ & 0.80 & - \\
\hline TBARS & $10.26(4.00)$ & $10.93(5.66)$ & $8.93(2.66)$ & $0.03 *$ & $N M>M$ \\
\hline PCC & $0.03(0.03)$ & $0.06(0.03)$ & $0.06(0.08)$ & $<0.001 *$ & $C<(N M=M)$ \\
\hline IL-2 & $0.25(0.08)$ & $0.27(0.12)$ & $0.24(0.07)$ & 0.65 & - \\
\hline IL-4 & $0.64(0.21)$ & $0.75(0.20)$ & $0.8 \mathrm{I}(0.37)$ & 0.06 & - \\
\hline IL-6 & $0.88(0.69)$ & $1.28(1.10)$ & $\mathrm{I} .45(2.55)$ & $0.01 *$ & $C<M$ \\
\hline IL-10 & $0.37(0.26)$ & $0.28(0.52)$ & $0.34(0.25)$ & 0.84 & - \\
\hline TNF- $\alpha$ & $0.98(0.30)$ & $0.97(0.29)$ & $1.02(0.35)$ & 0.69 & - \\
\hline IFN- $\gamma$ & $1.64(0.34)$ & $\mathrm{I} .64(0.72)$ & $1.45(0.39)$ & $0.01 *$ & $(C=N M)>M$ \\
\hline IL-I7 & $12.84(17.18)$ & $7.5 I$ (9.7) & $7.99(10.02)$ & 0.22 & - \\
\hline
\end{tabular}

Notes: All analysis comparing three groups: control, nonmelancholic, and melancholic groups according to the two models. BDNF is displayed as the mean \pm standard deviation; other variables are displayed as the median and interquartile range. The last column shows a post hoc comparison between groups according to one-way analysis for BDNF or Kruskal-Wallis test for other variables. *Indicates statistically significant $P$-values.

Abbreviations: BDNF, brain-derived neurotrophic factor; TBARS, thiobarbituric acid reactive substances; PCC, protein carbonyl content; IL-2, interleukin-2; IL-4, interleukin-4; IL-6, interleukin-6; IL-I0, interleukin-10; IL-I7, interleukin-I7; TNF- $\alpha$, tumor necrosis factor-alpha; IFN- $\gamma$, interferon-gamma; NM, nonmelancholic group; $\mathrm{M}$, melancholic group; C, control group.

First, we compared all depressed patients (irrespective of any subdivision) with controls in relation to potential neurobiological markers. We found that PCC, IL-4, and IL-6 values were higher in the depressive group, replicating previous studies. ${ }^{43,57-59}$ Other measures (BDNF, IL-2, IL-10, IFN- $\gamma$, TNF- $\alpha$, and IL-1 levels) failed to indicate any differences across groups.

The increase in IL-6 is one of the most consistently replicated findings in depressive patients, confirmed in a meta-analysis by Dowlati et a ${ }^{43}$ which also found increased TNF- $\alpha$ in depressed patients, albeit not replicated in the current study. The higher levels of IL-4 (a Th2 anti-inflammatory marker) in depressed patients compared with controls is a less consistent finding, with only a few studies reporting this ${ }^{58,59}$ and a meta-analysis finding no differences. ${ }^{43}$ In relation to oxidative stress, the increase in carbonyl products (PCC) in our depressive patients is consistent with a study by Magalhaes et al in unipolar depressed subjects from a population-based sample. ${ }^{57}$ Whereas PCC has been found to be increased in those with a bipolar disorder, ${ }^{57,60}$ more studies are needed to examine this in patients with unipolar depression. Our findings did not replicate the higher TBARS ${ }^{49}$ and lower BDNF ${ }^{61}$ values in depression reported by previous studies, and may reflect some limitations to our study (discussed below).

In addition to the differences in neurobiological parameters between patients with depression and controls described above, we also found biological differences between subsets of depressive patients (melancholic and nonmelancholic) using the CORE subtyping measure. While differences in PCC between depressive patients and controls were evident in both depressive subgroups (with no differences between those subsets), differences in the inflammatory marker IL-6 were limited to the melancholic subset in comparison with the control group. Moreover, the statistical difference between depressive patients and controls in IL-4 disappears, whereas differences emerge between depressive subsets in IFN- $\gamma$ and TBARS, with melancholic participants achieving lower IFN- $\gamma$ (than both nonmelancholic patients and controls) and TBARS (than nonmelancholic) values.

While there were no differences in the Th1 proinflammatory marker IFN- $\gamma$ between depressive patients and controls in the initial analysis, we found lower values in melancholic patients when the depressive groups were split according to clinical signs of PMD. This finding is consistent with a study by Rothermundt et $\mathrm{al}^{10}$ who found lower IFN- $\gamma$ and IL-2 levels in melancholic patients, using a symptom-based definition of melancholia. They suggested a decrease in cell-mediated immunity in patients with melancholic depression, possibly induced by hypercortisolemia. Thereby, while melancholic depression is classically associated with hypercortisolemia ${ }^{62}$ and an increase in plasma adrenocorticotropic hormone, ${ }^{18}$ this increase added to an increase in catecholamines (the major stress hormones) may systematically inhibit the Th1 proinflammatory response (via IFN- $\gamma$ ), while upregulating Th2 anti-inflammatory production (via IL-4) ${ }^{63}$ A possible explanation for our results is that melancholic depression may be represented by a specific dysregulation of the proinflammatory/anti-inflammatory and Th1/Th2 cytokine balance, with a sustained increase in hypercortisolemia and catecholamines that then upregulate IL-6 levels. 
Although the initial higher IL-4 value was not statistically significant when we split the depressive group into subsets, this change may reflect our small sample size and limited statistical power. Similarly, the significance of the higher IL-6 value was limited to melancholic patients when compared with controls, with no differences between depressive subtypes when directly compared. Although increased IL-6 is a well established change in depression ${ }^{43}$ and is more distinctive in melancholic than nonmelancholic patients, ${ }^{27}$ our small sample subsets may have compromised our ability to demonstrate any such difference.

Turning to oxidative stress markers, the difference in PCC was sustained in both depressive subsets when compared with controls, with no difference between subsets. The lack of ability of PCC to discriminate depressive subgroups may be more a reflection of "depression" than of depressive "subtype". In addition, PCC is not only a sign of oxidative stress, but also of protein dysfunction. Carbonyl products are altered in a number of systemic diseases, including Alzheimer's disease, inflammation, and diabetes, ${ }^{64}$ are increased consistently in bipolar disorder, ${ }^{57}$ and may simply be a nonspecific marker of disease. Therefore, PCC may be seen as a sign of activity in mood disorders, rather than a marker of a specific subcategory. On the other hand, we found an initially counterintuitive decrease in TBARS, a measure of lipid oxidative stress, in melancholic patients in comparison with the nonmelancholic group. Most studies have found no changes ${ }^{57}$ or reported an increase ${ }^{48,65,66}$ in TBARS in depression. To our knowledge, no previous studies have investigated TBARS in melancholic depression, and this result clearly warrants replication as it may represent an indirect peripheral metabolic difference in depressive subsets. TBARS is a marker of lipid oxidation, and is altered according to metabolic status. ${ }^{67}$ However, our sample subtyped by PMD did not differ regarding body mass index. Previous studies have used symptoms to subtype depressive patients (where nonmelancholic subsets may include atypical depression) and differentiate them according to patterns of changes in weight and appetite (increased in atypical depression and decreased in melancholia). For instance, Lamers et $\mathrm{al}^{26}$ found minimal or no difference between melancholic patients and healthy controls across several metabolic parameters, although their melancholic patients had lower values for some variables (waist circumference and body mass index). On the other hand, atypical (nonmelancholic) depression was associated with much greater metabolic dysregulation compared with both melancholic patients and controls. In that study, Lamers et al used a modified method to rate depressive subsets, with symptoms of weight and appetite distinctly differentiating the subgroups of depression. Although we did not evaluate atypical depression or other metabolic markers in our study, and body mass index values were no different between subsets, other metabolic differences between depressive subsets might be a putative explanation for this finding.

Most studies examining biological differences (including inflammatory markers) in melancholic patients have made comparisons with symptom-defined groups with nonmelancholic depression, atypical depression, or nondepressive controls. ${ }^{9-11,18,27,29-32,34,35,68}$ Such studies have generally reported hypercortisolemia and other hypothalamic-pituitary-adrenal axis changes in melancholic patients ${ }^{11,18,32,34,69}$ but contradictory or less robust results in relation to inflammatory markers. These contradictory results may reflect limitations of symptom-based criteria in accurately discriminating the melancholic depressive subtype. ${ }^{70}$ Our results bring a contribution, demonstrating that a sign-based criteria set might help to refine the diagnosis of melancholia, advancing the search for biological determinants of depressive disorder, with potential therapeutic implications.

Our study had a number of limitations. First, the sample was small, so had limited statistical power. Second, all patients were taking psychiatric medications. Although no differences were found in medication classes among the groups, antidepressants and neuroleptic medications may change inflammatory biomarkers, ${ }^{10,71}$ levels of BDNF, ${ }^{46}$ and oxidative stress parameters..$^{49,66,72}$ Third, other potential variables associated with changes in biomarkers were not evaluated, including nutritional status ${ }^{73}$ and menstrual cycle. ${ }^{74}$ Fourth, although observational rating of PMD is necessary when using the CORE measure, observable PMD has been shown to be less distinctive in younger patients with seemingly true melancholic depression, while a valid rating of PMD requires observing patients at or near the nadir of their depressive episode. ${ }^{6}$ While auxiliary tools are being developed to complement the assessment, such as the Sydney Melancholia Prototype Index, ${ }^{6}$ only the CORE measure was used in the current study.

Diagnoses such as major depression comprise subsets of depressive conditions, and there is evidence that each may have differing causes, illness trajectories, and treatment responses. Valid identification of one historically weighted subset condition (ie, melancholia) may be clinically helpful, and our results add to the body of evidence suggesting that this differentiation may contribute to 
understanding the underlying neurobiology. Although psychiatry disorders are generally defined by symptoms, clinically observable signs can lead to a more accurate diagnosis of melancholia and should be considered in future research studies.

\section{Conclusion}

Depressive patients differed from healthy controls on three biological parameters, returning higher PCC, IL-4, and IL-6 values. Melancholic patients classified by a sign-based measure (CORE) scored lower across lipid oxidative stress markers (versus nonmelancholic patients) and immunological markers (versus both controls and nonmelancholic patients). A sign-based measure (CORE) used to subtype depressive patients demonstrated biological differences across depressive subsets and might enhance accuracy of the clinical diagnosis of melancholia. The limitations of our study were that: its small sample size may have limited its analytic power; all patients were on medication, a potential confounding variable in relation to measuring biological data; and the fact that younger patients may show less PMD, limiting the power of the CORE measure in this population.

\section{Disclosure}

The authors report no conflicts of interest in this work.

\section{References}

1. Fink M, Bolwig TG, Parker G, Shorter E. Melancholia: restoration in psychiatric classification recommended. Acta Psychiatr Scand. 2007;115(2):89-92.

2. Roth M. Unitary or binary nature of classification of depressive illness and its implications for the scope of manic depressive disorder. $J$ Affect Disord. 2001;64(1):1-18.

3. Parker G. Classifying depression: should paradigms lost be regained? Am J Psychiatry. 2000;157(8):1195-1203.

4. Caldieraro MA, Baeza FL, Pinheiro DO, Ribeiro MR, Parker G, Fleck MP. Clinical differences between melancholic and nonmelancholic depression as defined by the CORE system. Compr Psychiatry. 2013;54(1):11-15.

5. Snowdon J. Should psychomotor disturbance be an essential criterion for a DSM-5 diagnosis of melancholia? BMC Psychiatry. 2013;13:160.

6. Parker G, McCraw S, Blanch B, Hadzi-Pavlovic D, Synnott H, Rees AM. Discriminating melancholic and non-melancholic depression by prototypic clinical features. J Affect Disord. 2013;144(3):199-207.

7. Lamers F, de Jonge P, Nolen WA, et al. Identifying depressive subtypes in a large cohort study: results from the Netherlands Study of Depression and Anxiety (NESDA). J Clin Psychiatry. 2010;71(12):1582-1589.

8. Gili M, Roca M, Armengol S, Asensio D, Garcia-Campayo J, Parker G. Clinical patterns and treatment outcome in patients with melancholic, atypical and non-melancholic depressions. PLoS One. 2012;7(10):e48200.

9. Rothermundt M, Arolt V, Peters M, et al. Inflammatory markers in major depression and melancholia. J Affect Disord. 2001;63(1-3):93-102.

10. Rothermundt M, Arolt V, Fenker J, Gutbrodt H, Peters M, Kirchner H. Different immune patterns in melancholic and non-melancholic major depression. Eur Arch Psychiatry Clin Neurosci. 2001;251(2): 90-97.
11. Karlovic D, Serretti A, Vrkic N, Martinac M, Marcinko D. Serum concentrations of CRP, IL-6, TNF-alpha and cortisol in major depressive disorder with melancholic or atypical features. Psychiatry Res. 2012;198(1):74-80.

12. Gold PW, Chrousos GP. Melancholic and atypical subtypes of depression represent distinct pathophysiological entities: $\mathrm{CRH}$, neural circuits, and the diathesis for anxiety and depression. Mol Psychiatry. 2013; 18(6):632-634.

13. Parker G, Fink M, Shorter E, et al. Issues for DSM-5: whither melancholia? The case for its classification as a distinct mood disorder. Am J Psychiatry. 2010;167(7):745-747.

14. Parker G, Hyett MP, Friend P, Hadzi-Pavlovic D. Does age impact on rating melancholic and non-melancholic depressive symptoms? J Affect Disord. 2013;147(1-3):318-324.

15. Carroll BJ, Feinberg M, Greden JF, et al. A specific laboratory test for the diagnosis of melancholia. Standardization, validation, and clinical utility. Arch Gen Psychiatry. 1981;38(1):15-22.

16. Davidson J, Lipper S, Zung WW, Strickland R, Krishnan R, Mahorney S. Validation of four definitions of melancholia by the dexamethasone suppression test. Am J Psychiatry. 1984;141(10):1220-1223.

17. Lu YR, Fu XY, Shi LG, et al. Decreased plasma neuroactive amino acids and increased nitric oxide levels in melancholic major depressive disorder. BMC Psychiatry. 2014;14(1):123.

18. Wong ML, Kling MA, Munson PJ, et al. Pronounced and sustained central hypernoradrenergic function in major depression with melancholic features: relation to hypercortisolism and corticotropin-releasing hormone. Proc Natl Acad Sci U S A. 2000;97(1):325-330.

19. Parker G, Hadzi-Pavlovic D. Prediction of response to antidepressant medication by a sign-based index of melancholia. Aust NZJPsychiatry. 1993;27(1):56-61.

20. Hickie I, Parsonage B, Parker G. Prediction of response to electroconvulsive therapy. Preliminary validation of a sign-based typology of depression. Br J Psychiatry. 1990;157:65-71.

21. Hickie I, Mason C, Parker G, Brodaty H. Prediction of ECT response: validation of a refined sign-based (CORE) system for defining melancholia. Br J Psychiatry. 1996;169(1):68-74.

22. Molendijk ML, Spinhoven P, Polak M, Bus BA, Penninx BW, Elzinga BM. Serum BDNF concentrations as peripheral manifestations of depression: evidence from a systematic review and meta-analyses on 179 associations (n=9,484). Mol Psychiatry. 2014;19(7):791-800.

23. Bus BA, Molendijk ML, Penninx BW, et al. Low serum BDNF levels in depressed patients cannot be attributed to individual depressive symptoms or symptom cluster. World J Biol Psychiatry. November 13, 2013. [Epub ahead of print]

24. Patas K, Penninx BW, Bus BA, et al. Association between serum brain-derived neurotrophic factor and plasma interleukin-6 in major depressive disorder with melancholic features. Brain Behav Immun. 2014;36:71-79.

25. Maes M, Galecki P, Chang YS, Berk M. A review on the oxidative and nitrosative stress (O\&NS) pathways in major depression and their possible contribution to the (neuro) degenerative processes in that illness. Prog Neuropsychopharmacol Biol Psychiatry. 2011;35(3): 676-692.

26. Lamers F, Vogelzangs N, Merikangas KR, de Jonge P, Beekman AT, Penninx BW. Evidence for a differential role of HPA-axis function, inflammation and metabolic syndrome in melancholic versus atypical depression. Mol Psychiatry. 2013;18(6):692-699.

27. Dunjic-Kostic B, Ivkovic M, Radonjic NV, et al. Melancholic and atypical major depression - connection between cytokines, psychopathology and treatment. Prog Neuropsychopharmacol Biol Psychiatry. 2013;43:1-6.

28. Maes M, Scharpe S, Meltzer HY, et al. Relationships between interleukin-6 activity, acute phase proteins, and function of the hypothalamic-pituitary-adrenal axis in severe depression. Psychiatry Res. 1993;49(1): 11-27.

29. Marques-Deak AH, Neto FL, Dominguez WV, et al. Cytokine profiles in women with different subtypes of major depressive disorder. JPsychiatr Res. 2007;41(1-2):152-159. 
30. Maes M, Mihaylova I, Kubera M, Ringel K. Activation of cell-mediated immunity in depression: association with inflammation, melancholia, clinical staging and the fatigue and somatic symptom cluster of depression. Prog Neuropsychopharmacol Biol Psychiatry. 2012;36(1): 169-175.

31. Huang TL, Lee CT. T-helper 1/T-helper 2 cytokine imbalance and clinical phenotypes of acute-phase major depression. Psychiatry Clin Neurosci. 2007;61(4):415-420.

32. Lamers F, Vogelzangs N, Merikangas KR, de Jonge P, Beekman AT, Penninx BW. Evidence for a differential role of HPA-axis function, inflammation and metabolic syndrome in melancholic versus atypical depression. Mol Psychiatry. 2012;18(6):692-699.

33. Hiles SA, Baker AL, de Malmanche T, Attia J. A meta-analysis of differences in IL- 6 and IL-10 between people with and without depression: exploring the causes of heterogeneity. Brain Behav Immun. 2012;26(7): 1180-1188

34. Kaestner F, Hettich M, Peters M, et al. Different activation patterns of proinflammatory cytokines in melancholic and non-melancholic major depression are associated with HPA axis activity. J Affect Disord. 2005; 87(2-3):305-311.

35. Schlatter J, Ortuno F, Cervera-Enguix S. Lymphocyte subsets and lymphokine production in patients with melancholic versus nonmelancholic depression. Psychiatry Res. 2004;128(3):259-265.

36. American Psychiatric Association DSM-5 Task Force. Diagnostic and Statistical Manual of Mental Disorders: DSM-5. Arlington, VA, USA: American Psychiatric Association; 2013.

37. Parker G, Hadzi-Pavlovic D, Boyce P, et al. Classifying depression by mental state signs. Br J Psychiatry. 1990;157:55-65.

38. Parker G, Hadzi-Pavlovic D, Wilhelm K, et al. Defining melancholia: properties of a refined sign-based measure. Br J Psychiatry. 1994; 164(3):316-326.

39. Parker G. Defining melancholia: the primacy of psychomotor disturbance. Acta Psychiatr Scand Suppl. 2007;(433):21-30.

40. Joyce PR, Mulder RT, Luty SE, et al. Melancholia: definitions, risk factors, personality, neuroendocrine markers and differential antidepressant response. Aust N Z J Psychiatry. 2002;36(3):376-383.

41. Attu SD, Rhebergen D, Comijs HC, Parker G, Stek ML. Psychomotor symptoms in depressed elderly patients: assessment of the construct validity of the Dutch CORE by accelerometry. J Affect Disord. 2012; 137(1-3):146-150.

42. Mitchell P. Validity of the CORE: I. A neuroendocrinological strategy. In: Parker G, Hadzi-Pavlovic D, editors. Melancholia: A Disorder of Movement and Mood. New York, NY, USA: Cambridge University Press; 1996.

43. Dowlati Y, Herrmann N, Swardfager W, et al. A meta-analysis of cytokines in major depression. Biol Psychiatry. 2010;67(5): 446-457.

44. Muller N, Myint AM, Schwarz MJ. Inflammatory biomarkers and depression. Neurotox Res. 2011;19(2):308-318.

45. Miller AH, Maletic V, Raison CL. Inflammation and its discontents: the role of cytokines in the pathophysiology of major depression. Biol Psychiatry. 2009;65(9):732-741.

46. Molendijk ML, Bus BA, Spinhoven P, et al. Serum levels of brainderived neurotrophic factor in major depressive disorder: state-trait issues, clinical features and pharmacological treatment. Mol Psychiatry. 2011;16(11):1088-1095.

47. Yoshida T, Ishikawa M, Niitsu T, et al. Decreased serum levels of mature brain-derived neurotrophic factor (BDNF), but not its precursor proBDNF, in patients with major depressive disorder. PLoS One. 2012; 7(8):e42676

48. Sarandol A, Sarandol E, Eker SS, Erdinc S, Vatansever E, Kirli S. Major depressive disorder is accompanied with oxidative stress: short-term antidepressant treatment does not alter oxidative-antioxidative systems. Hum Psychopharmacol. 2007;22(2):67-73.

49. Ng F, Berk M, Dean O, Bush AI. Oxidative stress in psychiatric disorders: evidence base and therapeutic implications. Int J Neuropsychopharmacol. 2008;11(6):851-876.
50. Amorim P. Mini International Neuropsychiatric Interview (MINI): validação de entrevista breve para diagnóstico de transtornos mentais [validation of a short structured diagnostic psychiatric interview]. Rev Bras Psiquiatr. 2000;22:106-115. Portuguese.

51. Black Dog Institute. The CORE assessment of psychomotor change: user's guide rating guidelines and items; 1996. Available from: http://www.blackdoginstitute.org.au/docs/corebooklet.pdf. Accessed July 14,2014

52. Parker G, Hadzi-Pavlovic D, Hickie I, et al. Sub-typing depression, III. Development of a clinical algorithm for melancholia and comparison with other diagnostic measures. Psychol Med. 1995;25(4): 833-840.

53. Hamilton M. A rating scale for depression. J Neurol Neurosurg Psychiatry. 1960;23:56-62.

54. Zimmerman M, Martinez JH, Friedman M, Boerescu DA, Attiullah N, Toba C. How can we use depression severity to guide treatment selection when measures of depression categorize patients differently? J Clin Psychiatry. 2012;73(10):1287-1291.

55. Levine RL, Garland D, Oliver CN, et al. Determination of carbonyl content in oxidatively modified proteins. Methods Enzymol. 1990; 186:464-478.

56. Shapiro SS, Wilk MB. An analysis of variance test for normality (complete samples). Biometrika. 1965;52(3-4):591-611.

57. Magalhaes PV, Jansen K, Pinheiro RT, et al. Peripheral oxidative damage in early-stage mood disorders: a nested population-based case-control study. Int J Neuropsychopharmacol. 2012;15(8): 1043-1050.

58. Pavon L, Sandoval-Lopez G, Eugenia Hernandez M, et al. Th2 cytokine response in major depressive disorder patients before treatment. J Neuroimmunol. 2006;172(1-2):156-165.

59. Hernandez ME, Mendieta D, Martinez-Fong D, et al. Variations in circulating cytokine levels during 52 week course of treatment with SSRI for major depressive disorder. Eur Neuropsychopharmacol. 2008; 18(12):917-924.

60. Kapczinski F, Dal-Pizzol F, Teixeira AL, et al. Peripheral biomarkers and illness activity in bipolar disorder. J Psychiatr Res. 2011;45(2): 156-161.

61. Fernandes BS, Berk M, Turck CW, Steiner J, Goncalves CA. Decreased peripheral brain-derived neurotrophic factor levels are a biomarker of disease activity in major psychiatric disorders: a comparative metaanalysis. Mol Psychiatry. 2014;19(7):750-751.

62. Carroll BJ, Greden JF, Feinberg M, et al. Neuroendocrine dysfunction in genetic subtypes of primary unipolar depression. Psychiatr Res. 1980; 2(3):251-258

63. Calcagni E, Elenkov I. Stress system activity, innate and T helper cytokines, and susceptibility to immune-related diseases. Ann N Y Acad Sci. 2006;1069:62-76.

64. Dalle-Donne I, Rossi R, Giustarini D, Milzani A, Colombo R. Protein carbonyl groups as biomarkers of oxidative stress. Clin Chim Acta. 2003:329(1-2):23-38.

65. Stefanescu C, Ciobica A. The relevance of oxidative stress status in first episode and recurrent depression. J Affect Disord. 2012;143(1-3): 34-38.

66. Bilici M, Efe H, Koroglu MA, Uydu HA, Bekaroglu M, Deger O. Antioxidative enzyme activities and lipid peroxidation in major depression: alterations by antidepressant treatments. J Affect Disord. 2001; 64(1):43-51.

67. Papandreou C, Schiza SE, Tzatzarakis MN, et al. Effect of Mediterranean diet on lipid peroxidation marker TBARS in obese patients with OSAHS under CPAP treatment: a randomised trial. Sleep Breath. 2012; 16(3):873-879.

68. Hickie I, Hickie C, Lloyd A, Silove D, Wakefield D. Impaired in vivo immune responses in patients with melancholia. BrJ Psychiatry. 1993; 162:651-657.

69. Stetler C, Miller GE. Depression and hypothalamic-pituitary-adrenal activation: a quantitative summary of four decades of research. Psychosom Med. 2011;73(2):114-126. 
70. Parker G, Brotchie H. [Major depression invites major concerns]. Rev Bras Psiquiatr. 2009;31 Suppl 1:S3-S6. Portuguese.

71. Sutcigil L, Oktenli C, Musabak U, et al. Pro- and anti-inflammatory cytokine balance in major depression: effect of sertraline therapy. Clin Dev Immunol. 2007;2007:76396.

72. Jeding I, Evans PJ, Akanmu D, et al. Characterization of the potential antioxidant and pro-oxidant actions of some neuroleptic drugs. Biochem Pharmacol. 1995;49(3):359-365.
73. Huang CJ, Fwu ML. Degree of protein deficiency affects the extent of the depression of the antioxidative enzyme activities and the enhancement of tissue lipid peroxidation in rats. $J$ Nutr. 1993;123(5):803-810.

74. Cubeddu A, Bucci F, Giannini A, et al. Brain-derived neurotrophic factor plasma variation during the different phases of the menstrual cycle in women with premenstrual syndrome. Psychoneuroendocrinology. 2011;36(4):523-530.

\section{Publish your work in this journal}

Neuropsychiatric Disease and Treatment is an international, peerreviewed journal of clinical therapeutics and pharmacology focusing on concise rapid reporting of clinical or pre-clinical studies on a range of neuropsychiatric and neurological disorders. This journal is indexed on PubMed Central, the 'PsycINFO' database and CAS, and is the official journal of The International Neuropsychiatric Association (INA). The manuscript management system is completely online and includes a very quick and fair peer-review system, which is all easy to use. Visit http://www.dovepress.com/testimonials.php to read real quotes from published authors.

Submit your manuscript here: http://www.dovepress.com/neuropsychiatric-disease-and-treatment-journal 